\title{
Atendimento a idosos: situações documentadas no Ministério Público do Estado do Rio de Janeiro
}

\author{
Rosanete Steffenon \\ Mestre em Serviço Social (Universidade Federal do Rio de Janeiro) \\ Assistente Social da Secretaria de Estado de Planejamento e Gestão - Vassouras \\ Professora no Centro Universitário Geraldo Di Biase - Volta Redonda e Barra do Piraí \\ Vassouras, Rio de Janeiro, Brasil \\ rosanetecf@gmail.com
}

\begin{abstract}
Resumo Nas últimas décadas observam-se mudanças na estrutura populacional, no âmbito legal, na família e em outras instituições no que diz respeito aos idosos. Isto, entre outros aspectos, contribui para colocar em discussão o atendimento a esse segmento da população. Nesse sentido, este artigo apresenta situações em que os direitos sociais básicos dos idosos não foram efetivados de forma integral, sendo, por isso, acionado o Ministério Público do Estado do Rio de Janeiro, por meio de suas Promotorias do Idoso. Assim, este texto apresenta situações documentadas em procedimentos administrativos das referidas promotorias e revela como idosos, famílias e demais envolvidos colocam-se em face de demandas não atendidas e de indicações para que idosos vivam em uma Instituição de Longa Permanência.
\end{abstract}

Palavras-chave: idosos, família, legislações.

\section{Introdução}

A partir de 2003, os idosos passaram a ter uma legislação específica, o Estatuto do Idoso, que representa também o reconhecimento estatal de suas demandas. A Lei n. 10.741, de $1^{\circ}$ de outubro de 2003, que o instituiu, preconiza que é obrigação da família, da comunidade, da sociedade e do Poder Público assegurar aos idosos, com absoluta prioridade, um conjunto de direitos (Brasil, 2003).

Este artigo pretende discutir situações de idosos que não têm parte dos seus direitos sociais básicos efetivados e, diante disso, são acionadas instituições para além da família, entre elas, as Promotorias do Idoso do Ministério Público. Assim, o artigo atenta especialmente para situações em que é indicada a necessidade de o idoso residir em uma Instituição de Longa Permanência para Idosos (ILPI). ${ }^{1}$

A análise aqui apresentada dialoga com aportes teóricos, com elementos presentes em legislações e em situações de idosos documentadas em Procedimentos Administrativos (PAs) das Promotorias do Idoso e da Pessoa com Deficiência da Capital, ${ }^{2}$ do Ministério Público do Estado do Rio de Janeiro. Além disso, engloba algumas observações rea-

1. A Lei n. 10.741 utiliza a expressão "abrigamento" para denominar a vivência em ILPI.

2. As Promotorias têm atuação também na área da pessoa não idosa com deficiência, porém essas ações não serão aqui abordadas, pois não é esse o enfoque do artigo. Assim e para favorecer a leitura, no decorrer do texto restringirei o nome à Promotoria do Idoso. 
lizadas em dois tempos da minha prática profissional em Serviço Social, realizada no Ministério Público. ${ }^{3}$

Este artigo menciona informações contidas em PAs das referidas Promotorias, as quais atuam à luz de legislações, utilizando, portanto, os termos presentes nelas. Neste sentido, cumpre esclarecer que usarei a expressão "abrigamento" quando me referir à vivência de idoso em ILPI, termo corrente nos PAs analisados e no Estatuto do Idoso, uma das principais legislações consideradas nas atuações das citadas Promotorias ${ }^{4}$ e nas intervenções voltadas aos idosos na contemporaneidade.

Inicialmente o artigo apresentará elementos históricos da constituição de políticas voltadas aos idosos e da configuração de Promotorias específicas no Ministério Público. Em seguida, trará considerações sobre a pesquisa documental realizada naquela instituição, para posteriormente apresentar aspectos contidos em três procedimentos administrativos (PAs) referentes a um idoso e duas idosas e outras situações observadas na prática profissional em Serviço Social. Ao longo deste artigo utilizar-se-ão nomes fictícios para os idosos e as Promotorias não serão identificadas, nem seus promotores.

\section{Idosos, legislações e Ministério Público}

O processo de mudanças na estrutura populacional ${ }^{5}$ torna visível o aumento do número de idosos e a necessidade de atenção específica para esse segmento etário. A velhice passa a ter visibilidade nas últimas décadas, decorrente de transformações na família, no trabalho, nos espaços de sociabilidade e com o movimento dos aposentados na década de 1990 (Lins de Barros, 2004).

Nesse bojo é que foram constituídas as políticas sociais para os idosos. A representação do avanço da idade como um processo de perdas, em que os indivíduos ficariam relegados a uma situação de abandono, de desprezo e de ausência de papéis sociais, contribuiu para a universalização da aposentadoria, a criação de leis protetivas, a realização de conferências e a elaboração de planos internacionais para o envelhecimento.

O Plano Internacional de Ação para o Envelhecimento (1982), do qual o Brasil foi signatário, resultou da I Assembleia Mundial sobre o Envelhecimento, convocada pela Organização das Nações Unidas, realizada em Viena, em 1982. Esse Plano indicou a adoção de um conceito ativo e positivo do envelhecimento e de ações que visassem a vivência saudável nessa etapa da vida. Sob essa influência, e conforme o Art. 230, a Constituição Federal de 1988 afirmou ser dever da família, da sociedade e do Estado o amparo ao idoso, a ser prestado "preferencialmente em seus lares"(Brasil, 1988).

Essa questão foi reafirmada pela Política Nacional do Idoso (Lei n. 8.842/1994), que, entre suas diretrizes, indica, no Art. 4, alíneas III e VIII, a primazia do atendimento ao idoso pela família, à exceção daqueles que não possuam condições que garantam sua própria subsistência, se desabrigados e sem família (Brasil, 1994). Em 2003, o Estatuto do Idoso (Lei n. 10.741) reafirma, nos artigos 43,44 e 45 , a priorização do atendimento pela família e prevê o abrigo "em entidade" e o "temporário" como medidas de proteção, quando há violação ou ameaça aos direitos do idoso (Brasil, 2003).

Com essa legislação, o Ministério Público passa a ter atribuições em prol da pessoa idosa e, assim, são constituídas Promotorias específicas. Na cidade do Rio de Janeiro, há atualmente cinco Promotorias do Idoso e da Pessoa com Deficiência, criadas ao longo de um processo iniciado em 2005 e que abrange a instalação da quinta Promotoria em 2012. As cinco Promotorias desempenham as mesmas atribuições, dividindo a atuação entre si por áreas de abrangência geográfica da capital.

As ações iniciam-se principalmente a partir de comunicações/denúncias que dão ciência à instituição de situações de violação de direitos do idoso. A comunicação, quando protocolada e reconhecida como atribuição da instituição, origina procedimento administrativo, cujo andamento comporta a análise da situação e a aplicação de medidas. Nesse processo, o Serviço Social da instituição e, em alguns casos também de outras, é solicitado a avaliar a situação informada na denúncia, o que geralmente é feito por meio de visitas domiciliares e entrevistas documentadas em relatórios sociais que são juntados aos PAs.

Os PAs materializam vários olhares e interpretações sobre a situação do idoso. Os registros que os configuram variam conforme os casos, mas de modo geral observou-se que são escritos por assistentes sociais, psiquiatras, promotores e funcionários administrativos de ouvidorias e das Promotorias. Em parte dos casos há também relatórios de psicólogos, e documentos formulados por gestores de instituições variadas ou escrito pelo próprio idoso, por familiares

\footnotetext{
3. Trata-se de um ano de estágio e de onze meses de atuação como assistente social.

4. Os termos utilizados para denominar a velhice e as formas de atendimento são produto e produtores de sentidos e analisá-los constituiria um debate interessante, ,porém, não é objetivo deste texto discuti-los.
}

5. Sobre as inflexões na pirâmide etária, ver Wong e Carvalho (2006) e IBGE (2010). 
e outros de sua convivência. Em suma, os PAs são compostos por documentos que trazem a transcrição literal de falas e ou a reelaboração e interpretação por profissionais daquilo que ouvem e observam.

\section{A pesquisa documental}

Realizada no período de novembro de 2011 a fevereiro de 2013, a pesquisa documental foi autorizada pelo Ministério Público do Estado do Rio de Janeiro. Foram inicialmente consultadas as comunicações feitas à instituição no segundo semestre de 2010, elaboradas pelo Serviço Social nas Promotorias do Idoso. O recorte temporal deve-se ao fato de a pesquisa buscar informações agregadas ao longo de no mínimo um ano, para assim não se restringir à visão primeira sobre a situação do idoso.

A escolha de documentos elaborados naqueles atendimentos, denominados representações, ${ }^{6}$ considerou que essa forma de redação possui um formato comum, ou seja, contém os mesmos pontos a serem informados, Entre eles, o vínculo do comunicante com o idoso, dado que não é exigido nas comunicações via ouvidorias.

A leitura de todas as representações constituídas em atendimentos realizados pelo Serviço Social de julho a dezembro de 2010 visou inicialmente separar aquelas que tratavam da necessidade de abrigo do idoso. Foram identificadas 17 representações, relativas a 18 idosos, pois uma se referia a um casal. Posteriormente, foi feita, via intranet, a pesquisa dos PAs que ainda estavam em curso no Ministério Público, uma vez que após serem arquivados ou encaminhados para as Varas de Justiça não há mais acesso a eles. Foram identificados oito PAs ainda em andamento e as respectivas Promotorias em que estavam. Com isso, foi realizada a leitura integral das informações já contidas nesses oito Pas, com retornos bimensais às Promotorias para acompanhar as novas informações agregadas.

Ao analisar documentos institucionais, constatei que parte deles é produzida na interação entre profissional e atendido (família, idoso e outros), ou seja, o discurso escrito é uma produção, e não um dado, pois é pré-fabricado e construído pela interação que o atravessa (Blanchet; Gotman, 1992). Ademais, os relatórios sociais presentes nos PAs devem responder ao "despacho do Promotor" que os solicitou, ou seja, há uma direção do que documentar e o modo de fazê-lo que está definida a priori.

Neste sentido, conforme Vianna (2002), como bens administrativos, os documentos registram as- pectos parciais da realidade que resultam da conversão das falas em depoimentos escritos e destes em peças para a produção de uma decisão administrativa e/ou judicial. As condições de constrangimento das falas são dadas pela situação de estar perante profissionais e especialistas com poder de avaliação e decisão. Nisso, há a escolha do que deixar registrado ou do que silenciar ao longo do processo. Ademais, ao mesmo tempo em que cada caso é relatado em sua singularidade, é também submetido a uma lógica comum, dada pela elaboração padronizada e legal dos procedimentos adotados. A negociação do conteúdo a ser registrado ocorre entre os que são "objeto" do procedimento administrativo e os profissionais que os atendem. Além disso, expressam o formato das relações e das necessidades apresentadas e remodeladas legalmente e o embate das concepções morais e simbólicas capazes de definir uma família e um lugar para o idoso.

Com a leitura dos oito PAs e das 17 representações, foram feitas anotações e cópias das informações contidas, posteriormente organizadas por temas em tabelas, a partir dos seguintes eixos: a) dados básicos: número do PA, data da representação, gênero e idade do idoso, vínculo do comunicante; b) formas de apresentação da situação pelo comunicante, por terceiros e por membros do MP e de outras instituições; c) percursos institucionais e intervenções anteriores à representação no $\mathrm{MP}$ e via essa instituição; d) condições relatadas: saúde, moradia, convivência familiar e comunitária, situação econômico-financeira. A análise de parte dessas informações foi apresentada na minha dissertação de mestrado em Serviço Social (Steffenon, 2013).

Entre os oito PAs lidos em sua integralidade, foram escolhidos três, dos quais as situações dos idosos serão tratadas a seguir. A escolha desses três considerou os diferentes vínculos dos comunicantes, as diferentes formas de chamamento à família e de desfecho das situações. Ao mesmo tempo, os três casos, assim como os demais observados, trazem similitudes no que tange às responsabilidades atribuídas à família e ao Estado.

\section{Situações de idosos documentadas em Promotorias do Idoso}

Os casos dos idosos Roberto, Laura e Maria, ${ }^{7}$ que serão aqui detalhados para pensar sobre algumas questões, apresentam singularidades e um ponto em comum: nenhum deles solicita o abrigamento nem são favoráveis a ele. Roberto dirigiu-se às Promo-

6. Denomina-se representação a ação por meio da qual alguém em nome alheio defende interesse e direito alheio. Trata-se de elaboração escrita que apresenta dada situação e solicita a intervenção institucional.

7. Nomes fictícios 
torias do Idoso para solicitar intervenção que conduzisse à devolução da própria casa para nela residir, pois estaria alugada e sob a administração de um filho com quem ele morava. Informou haver divergências entre eles e que não voltaria à casa. Consta que ele apresentava "situação precária de higiene", dizia não ter se alimentado e que a sua aposentadoria, de um salário mínimo e meio, era administrada pelo filho. O promotor definiu que o idoso fosse abrigado temporariamente em instituição pública, o que foi feito de imediato. Seus três filhos compareceram à instituição de acolhimento e o idoso sugeriu morar com outro filho, que rejeitou a proposta informando não ter condições de assisti-lo, bem como o fez a filha. Ambos argumentaram que precisavam trabalhar e assim não dispunham de tempo, a filha também alegou ter problemas de saúde.

Neste sentido, se a coabitação, em parte dos casos, pode beneficiar tanto as gerações mais novas quanto as mais velhas, no que se refere às trocas de afeto, de serviços e de dinheiro (Lins de Barros, 1987; Alves, 2007; Peixoto, 2009),

não se sabe, por exemplo, se do ponto de vista dos idosos os arranjos familiares predominantes estão refletindo as suas preferências ou se são resultado de uma "solidariedade imposta". (...) essa pode ser resultado de pressões econômicas, sociais e/ou de saúde, seja de sua parte, seja da parte de seus filhos. O mesmo se passa com os demais membros da família. Esse é um ponto importante a ser considerado, porque pode ser um elemento desencadeador de insatisfação e violências domésticas. (Camarano, 2004, p. 145)

Diversos estudos revelam que, nas denúncias de violência contra idosos, o agressor é sempre próximo, em geral familiar. ${ }^{8}$ Isso não significa que nas instituições de abrigamento haja integral proteção e não violências, e sim que o caráter valorativo de proteção atribuído à família também é questionável.

No caso de Roberto, seus filhos sugeriram o abrigamento em uma instituição privada a ser custeada com o provento dele, afirmando que o único que poderia assisti-lo não fora aceito pelo pai. Assim, o idoso foi encaminhado a outra Unidade de acolhimento da assistência social para aguardar "providências de seus familiares". Posteriormente, ele foi levado para uma Instituição de Longa Permanência para Idosos (ILPI) filantrópica, na região de residência da família. Entre os documentos enviados ao Ministério Público (MP) por instituições consultadas, constou a informação de que Roberto teve internação em clínica psiquiátrica e que seria interditado, o que depois foi comprovado pela curadora, sua nora, com quem morou.
Após quase dois anos de acolhimento, a ILPI encaminhou cópia de "termo de desligamento", informando ao MP o retorno do idoso ao convívio familiar. A nora compareceu às Promotorias para entregar cópia do termo de curatela e, na ocasião, expôs que o idoso não retornou à casa, e sim passou a residir em outra ILPI, privada. No entanto, considerou-se a informação da instituição, e o PA foi encaminhado para arquivamento, com o argumento de que o idoso estaria sob a responsabilidade da família, mediante a curatela e a coabitação. O caso de Roberto teve andamento na Promotoria do Idoso durante 21 meses.

A situação da idosa Maria foi informada ao MP pela proprietária do imóvel onde morava sozinha, em condições insalubres. Ela guardava materiais recolhidos nas ruas e apresentava ferimentos nos membros inferiores. O promotor solicitou visitas domiciliares de assistentes sociais e de médicos. A idosa não foi receptiva e informou que tem um irmão com paralisia nos membros inferiores, o qual vive em ILPI, e outro que fizera cirurgia e estaria temporariamente sem condições para se locomover. Este e a cunhada a visitariam eventualmente. Nos relatórios que compõem o PA, foi apontada a necessidade de a família atender a idosa. O irmão que a visitava foi notificado e compareceu à Promotoria, onde informou estar doente e residir em quitinete, não tendo assim condições de saúde, nem espaço para acolher a irmã.

No decorrer do andamento do PA, foram feitas várias descrições da situação da idosa e do referido irmão, também idoso. Ademais, comunicações anônimas e feitas pelo porteiro enfatizaram o agravamento dos problemas dela. Considerando as informações que reiteravam que Maria não teria como residir sozinha, e principalmente com base em laudo médico que afirmava "início de quadro de demência senil", o promotor encaminhou o caso para a Vara de Justiça para processo de interdição civil. No documento direcionado ao juiz, o promotor elegeu informações que indicavam a presença do irmão na vida da idosa e suprimiu as que informavam dificuldades da família para atendê-la.

Assim, na Promotoria do Idoso, a situação dessa idosa, cujo PA teve andamento durante 19 meses, se encerrou com a proposição de ter preferencialmente um familiar que por via judicial será o curador e responsável por ela. Mas esse mecanismo legal, por si só, não garante a proteção do idoso nem soluciona os problemas daqueles que não têm como atender às suas necessidades.

Conforme Jelin (2009), a família não é instituição isolada. Os lugares e as organizações familiares relacionam-se com o mercado de trabalho e a organização de redes sociais, e por isso aspectos como ta- 
xas de fecundidade, de divórcio, envelhecimento, são parte de processos sociais e culturais mais amplos que também deveriam estar sujeitos a políticas públicas.

As políticas sociais situam as famílias como foco e colocam-nas em posição prioritária para o atendimento aos dependentes, o que se soma a ausência de serviços sociais efetivos. Assim, a família se vê obrigada a assumir o encargo, mesmo que não tenha condições e laços afetivos. Ademais, ainda prevalece concepção naturalizada de família, que enfatiza relações de descendência e consanguinidade.

Tradicionalmente, a maioria das políticas governamentais é concebida a partir de um conceito de família "funcional", em que há a presença de pai e mãe vinculados por matrimônio, com perspectiva de convivência de longa duração, filhas e filhos próprios e os papéis de gênero estão perfeitamente definidos: as mulheres responsabilizadas pelos trabalhos domésticos e os homens pelos extra-domésticos. (Arriagada, 2007, p. 231)

No entanto, a família não segue "narrativa linear padrão" nem pode ser reduzida à unidade natural, pois é espaço poroso perpassado por forças e relações que se estendem para além do espaço doméstico (Fonseca, 2007). Dessa forma, a família não é apenas um conjunto de pessoas unidas por laços de consanguinidade ou dependência, pois também é composta por indivíduos que vivem no cotidiano "um jogo de poder que se cristaliza na distribuição dos direitos e deveres a cada um de seus membros" (Coutinho, 2006, p. 96). A organização ampliada das relações familiares pode realizar-se para além da família nuclear, incluindo parentes por consideração (Guedes; Lima, 2006). Destarte, o pertencimento familiar é também influenciado pelas situações. "Em determinados momentos ou para determinados objetivos, os afins podem ou não ser incluídos na trama (ao lado dos parentes 'naturais', de sangue). Em casos extremos, alguns dos consanguíneos podem ser excluídos desse entrelaçamento" (Duarte; Gomes, 2008, p. 162).

No caso da idosa Laura, sua situação chegou às Promotorias do Idoso por meio de uma vizinha. Esta informou que Laura morava em imóvel alugado, interditado pela Prefeitura e com indicação de demolição. É viúva, genitora de uma única filha, já falecida, da qual tem dois netos adolescentes, com quem tem pouco contato. Acolhe um amigo na residência. Perdeu toda a documentação em uma catástrofe ambiental, não possui renda e vive de benesses. A vizinha solicitara providências quanto à documentação da idosa em diferentes instituições - Defensoria Pública,
Tribunal Regional Eleitoral (TRE), Fundação Leão XIII, Departamento Estadual de Trânsito (Detran) e Instituto Félix Pacheco (IFP) - todas sem exito e sob a mesma alegação: a de não ter sido localizado o cartório onde a idosa fora registrada, em outro estado da federação.

Laura aparentaria condições de saúde para gerenciar seu cotidiano. Utilizaria, por conta própria, medicação para controle da pressão arterial, doada por membro de uma igreja local, da qual recebia cesta básica. Por solicitação do promotor, foram realizadas, em duplicidade, visitas domiciliares de profissionais de Serviço Social e da área médica. Esses ratificaram as informações apresentadas pela vizinha e enfatizaram a necessidade de providências quanto à documentação da idosa para possibilitar o acesso a direitos sociais básicos, dentre eles, a moradia. Após quinze meses da comunicação, a idosa foi notificada e compareceu ao MP.

Diante do promotor, Laura repetiu as informações anteriormente expostas pela vizinha, que a acompanhou. O promotor recomendou que elas retornassem à Defensoria Pública para providências quanto à documentação, argumentando que a idosa apresentava condições de buscar os próprios direitos, não necessitando assim da tutela do MP.

Posteriormente, sob a ótica de outro promotor que assumiu o caso, foram feitas solicitações de identificação datiloscópica da idosa e pesquisas em cartórios para a localização de sua documentação. Ademais, foi requerida a localização dos netos e a notificação para comparecimento a fim de avaliar se poderiam assistir a avó. Visitas domiciliares foram novamente solicitadas a profissionais que atuam na política de assistência social, os quais passaram a sugerir o abrigamento da idosa. Ante a recusa de Laura, argumentaram que ela estaria apresentando indícios de problemas de saúde mental e que o abrigamento seria viável para "facilitar a equipe técnica providenciar as documentações, cuidado à saúde, alimentação e moradia adequada, lazer e direitos, dentre eles, o BPC". 9

Em fevereiro de 2013, quando encerrei a pesquisa documental, o procedimento administrativo do caso da idosa ainda estava em andamento na Promotoria, onde fora iniciado há mais de dois anos. Aguardava resposta da avaliação psiquiátrica da idosa, dos órgãos de pesquisa documental e a localização de seus netos.

No caso dessa idosa, ela não reclamou a ausência de familiares nem solicitou a presença dos netos, que seriam seus parentes vivos mais próximos. A idosa considerava a vizinha como sua filha e esta a assistia de acordo com suas possibilidades. Neste sentido, conforme pontua Jelin (2009), para analisar a

9. Benefício de Prestação Continuada, previsto pela Lei Orgânica da Assistência Social (LOAS) ao idoso a partir dos 65 anos e à pessoa com deficiência de qualquer idade, desde que não possuam meios de garantir o próprio sustento, nem tê-lo provido por sua família. A renda mensal familiar per capita deve ser inferior a 1/4 do salário mínimo vigente. 
dinâmica dos vínculos familiares e de parentesco, é necessário um enfoque que privilegie as transições e os processos. No entanto, há uma forte significação simbólica e ideológica da família, cujos valores se expressam nas imagens de família "normal" e "natural". Nas políticas sociais ainda persiste essa ideia, o que comporta limites para considerar a pluralidade de formas de vida privada e os diferentes arranjos familiares contemporâneos (Goldani, 2005).

Os problemas vivenciados pela idosa Laura referem-se a questões materiais, e não familiares. $\mathrm{O}$ abrigamento é-lhe proposto, mas ela quer seus direitos básicos garantidos, principalmente previdência e moradia. Manifestou o desejo de ter uma casa "na beira da rua", isto é, não com os limites de acesso por degraus, como na comunidade onde morava. A idosa não poderia ser inscrita em programas assistenciais sem antes existir como cidadã, isto é, documentada. A não resolução disso indicou o abrigamento como solução e a rejeição dessa proposta por parte da idosa poderia ser interpretada como recusa a ser atendida. Além disso, Laura aparentava condições físicas para reclamar seus direitos e então, sob a ótica das Promotorias, teria responsabilidade própria para obtê-los. Por isso, fora indicado o retorno à Defensoria Pública, embora informasse já ter feito isso, sem êxito.

Essa realidade retrata a inexistência de articulação das responsabilidades entre família, Estado e demais instituições na garantia de direitos. Atribui-se a indivíduos e suas famílias o cumprimento de funções de amparo diante das crises econômicas, do desemprego, da enfermidade e da morte dos seus membros (Arriagada, 2007). Com isso, há uma suposição implícita de que as famílias, e, nelas, principalmente as mulheres, não incorrem em custos financeiros e/ou emocionais para o cuidado dos dependentes.

Conforme Lemos, Oliveira e Almeida (2012), "embora as configurações domésticas venham se modificando ao longo dos anos, em termos culturais há um forte condicionamento na relação entre a função do cuidado e a situação de gênero". Além disso, o caráter informal e invisibilizado dos cuidados familiares tende a considerar a questão como natural e orgânica do espaço familiar, e de função da figura feminina, o que produz também acusações às famílias/mulheres que não realizam esse cuidado, por falta de possibilidades ou por escolha (Engel, 2012).

Estudos no âmbito internacional constatam que a preocupação com os cuidados de longa duração nos países com populações mais envelhecidas buscou separar os crescentes custos com o tratamento de longa duração dos idosos dos demais gastos com saúde (Pasinato; Kornis, 2009). Desse modo, as decorrentes políticas buscam priorizar o atendimento aos idosos nos seus lares e/ou em comunidades, como forma de reduzir custos e com argumentos de proporcionar o bem-estar, além de desenvolver programas de cunho informativo, no intuito de apoiar os cuidadores informais, principalmente os familiares.

$\mathrm{Na}$ medida em que o encargo individual e familiar se dá em meio à intervenção do Estado, com parcas e fragmentadas políticas sociais que impõem ainda condicionalidades restritivas do acesso a direitos, é que se enfatizam, por parte do próprio Estado, os aspectos controladores das ações familiares. Com isso, coloca-se o dilema entre a garantia do direito à proteção e a garantia do direito à privacidade familiar. A "presença do Estado, por meio de seus agentes na família, não possui apenas uma face, ou uma intenção, pois, ao mesmo tempo em que protege, coloca em movimento estratégias de controle" (Mioto, 2010, p. 63).

Dadas a conjuntura neoliberal e "a predominância, em quase todo o mundo, de um modelo de políticas sociais que privilegia o enxugamento do Estado, as famílias estão sendo cada vez mais requeridas para cuidar dos seus segmentos "vulneráveis". (Camarano et al., 2004, p. 138). E com isso "independentemente de alterações e mudanças substantivas na composição e nos arranjos familiares, a família é um forte agente de proteção social de seus membros: idoso, doente crônico, dependentes, crianças, jovens, desempregados" (Carvalho, 2007, p. 274).

\section{Oposições à vivência em ILPI e ausência de alternativas}

De modo geral, durante minha prática profissional, observei nos atendimentos e visitas domiciliares e institucionais que os envolvidos relatam dificuldades para atender aos idosos, por causa da carência de recursos financeiros, da ausência de políticas de apoio, de conflitos intergeracionais, consanguíneos e afins, entre outras situações que são permeadas por constante responsabilização da família, que se vê pressionada e obrigada a dar respostas às novas situações para as quais muitas vezes não está preparada e não conta com apoios suficientes.

Nos três casos descritos - de Roberto, Maria e Laura -, as possibilidades de solução para suas demandas são olhadas a partir das suas próprias condições e as de suas famílias, e na falta delas é indicado o abrigamento. Os Centros-Dia, por exemplo, contribuiriam para a manutenção de idosos em suas casas, porém, embora previstos desde 1994 na Política Nacional do Idoso, sua implementação ainda é pequena e inexiste em vários lugares. Segundo aponta o estudo de Lemos, Oliveira e Almeida (2012), a estrutura de atendimento dos Centros-Dia não comporta a demanda do número de idosos que o procuram, e a ampliação 
dessa modalidade seria uma possibilidade para a manutenção dos vínculos familiares e a não institucionalização dos idosos em ILPIs. Além disso, constituiria uma política de apoio às famílias e que conjugaria as responsabilidades destas com as do Estado.

A situação econômica desfavorável é fator limitador do acesso a serviços. Nas visitas domiciliares realizadas, idosos verbalizaram suas situações por meio de falas como a seguinte: "É muito ruim ser um velho pobre", e acrescentaram o seu temor diante da possibilidade de a doença se agravar, do aluguel aumentar, de ter atendimento tardio pelo SUS, entre outras questões. As suas próprias necessidades em geral não são supridas com os recursos advindos de aposentadoria, de pensão ou do BPC. Ademais, na maioria dos casos, esses recursos são também utilizados por outros membros do domicílio e ou do núcleo familiar. Nas camadas pobres, o idoso tanto pode ser um empecilho para a família como a sua única fonte de renda, em forma de aposentadoria ou pensão (Goldman, 2004).

Na minha experiência profissional, encontrei situações de idosos com saúde fragilizada, morando sozinhos ou que ficavam sós na maior parte do tempo. Em geral, espontaneamente, ou quando perguntados sobre a possibilidade de abrigamento, eles manifestaram a recusa. Essas situações referem-se também a idosos sem recursos econômico-financeiros para remunerar cuidador que possa auxiliá-los. Informam gastos elevados com medicamentos e serviços de saúde, uma vez que por meio do SUS há demora para realizar exames clínicos, e não encontram atuação de fisioterapia, neurologia, entre outras especialidades, para prestar atendimento domiciliar àqueles com limites de locomoção.

Parte desses idosos conta com a ajuda voluntária de vizinhos para algumas ações, como comprar a alimentação. No entanto, quanto maior a dependência, mais difícil se torna essa contribuição. Ela pode realizar-se de forma mais sistemática se o idoso repassar alguma remuneração para, por exemplo, uma vizinha lavar suas roupas, outra preparar a alimentação, quiçá uma terceira para limpar o imóvel. Essas configurações de redes de apoio são sempre femininas e possíveis quando o idoso tem algum vínculo de vizinhança e de amizade estabelecido há mais tempo e recursos financeiros para remunerar o serviço.

Em geral os idosos recusam a possibilidade de abrigamento, o que é expresso com argumentos tais como os das seguintes falas: "Asilo é lugar triste porque tem muito velho, gente com problemas, um implica com o outro, e sempre morre alguém"; "Eu prefiro ir à frente de um ônibus para me atropelar do que ir para um asilo". Além disso, enfatizam: "Eu tenho a minha casa, as minhas coisas, não vou deixar isso aqui”; "Em casa está ruim, mas é o meu cantinho".
Em parte dos casos, que são raros, os idosos informam a intenção de ir para uma ILPI, e isso geralmente ocorre quando convivem com um único familiar que os agride, ou que faz uso de drogas e rejeita a possibilidade de tratamento. Isso ocorre quando consideram esgotadas as possibilidades de reverter a situação, e esta lhes coloca a vida em risco, no que tange à segurança e ao agravamento dos problemas de doença. Nesses casos, os idosos avaliam que, se houver determinação de afastamento do familiar do lar, não terão outro local para morar e, assim, requerem o próprio abrigamento. Entretanto, informam que se trata de uma "escolha" forçada.

Nos aspectos acima abordados estão presentes não só concepções sobre abrigamento, mas principalmente a ausência de outras possibilidades. No que tange às falas dos idosos, mostra-se a ideia de que as ILPIs são depósitos de velhos, e que misturam esses com pessoas problemáticas, "loucas", com mendigos sem casa e sem recursos, como nas primeiras configurações das instituições.

A resistência em entrar para uma ILPI pode ser entendida como medo que alguns velhos têm de não poder mais decidir sobre seu destino, suas vontades e seus desejos, de perder a liberdade, de ficar isolado da família - quando ela existe - e do mundo exterior. Mas não só. A reputação dessas instituições é negativa, pois elas são herdeiras das representações sociais dos antigos asilos e abrigos para velhos: lugares repugnantes, ambientes mórbidos, abusos de poder e maus-tratos. A imagem desses estabelecimentos e a internação involuntária significam, para muitos velhos, o equivalente a uma morte social que poderá se traduzir em uma morte real. (Billé, 2005 apud Peixoto, 2011)

Além disso, a entrada em uma instituição significa um rito de passagem que implica em desfazer-se de seus bens pessoais (a começar pela casa e objetos) para entrar em um cenário de vida com regras e ritmos (Peixoto, 2011) que interferem na privacidade e na liberdade de ir e vir.

Os cuidados institucionais voltados aos dependentes, principalmente crianças e idosos, são também carregados de preconceito, uma vez que há forte cunho moral e cultural que valoriza o cuidado familiar. Assim, com a norma social que atribui aos descendentes a responsabilidade pela geração mais velha, reforçada pelo aparato legal, recorrer a instituições de longa permanência é atitude polêmica e carregada de preconceitos, e quando a decisão pela institucionalização é tomada pela família a valoração negativa é mais forte (Camarano, 2007).

Neste sentido, conforme analisa Goldani (2005), vale atentar para a dificuldade em romper com os pa- 
péis atribuídos a homens e mulheres, pois persiste a ideia de que cuidar é tarefa familiar e feminina, o que é reforçado nos mecanismos legais e nas formas de implementação das políticas sociais. Isso remete também à questão da queda da fecundidade, cujas argumentações correntes, em geral, centram atenção apenas na entrada da mulher no mercado de trabalho, ocultando que esse ingresso veio desacompanhado de suporte para o cuidado dos filhos.

A política de assistência social preconiza ações específicas para os idosos. Na proteção social básica, além do BPC, estão previstos o Serviço de Fortalecimento de Vínculos e o Serviço de Proteção Básica no Domicílio. O primeiro é basicamente realizado por meio de grupos de convivência de idosos, o que significa o atendimento àqueles que têm condições de transitar no espaço público. O segundo é viabilizado por intermédio de visitas domiciliares e visa contribuir para o acesso a outras políticas públicas e desenvolver ações de apoio, informação, orientação e encaminhamento, com foco na qualidadede vida, exercício da cidadania e prevenção do isolamento. Em estudo elaborado por Delgado e Flor (2012) na cidade de Salvador, constatou-se que principalmente o Serviço de Proteção Básica no Domicílio não estava ocorrendo de forma efetiva, em parte porque não há repasse financeiro para que seja realizado. De modo semelhante, pode-se presumir que no Rio de Janeiro ele também não é viabilizado, uma vez que os idosos visitados por assistentes sociais do Ministério Público informam desconhecer a existência do referido serviço.

Assim, se por um lado, a legislação relativa aos idosos apresenta o abrigamento como medida excepcional; por outro, cresce o número de idosos com necessidades básicas não atendidas. Disso decorrem indicações de abrigamento em instituições que oferecem serviços de longa permanência, embora os próprios idosos geralmente recusem essa medida.

Diante disso, observa-se que as Promotorias do Idoso atuam concomitantemente sob duas lógicas distintas, que são tensionadas. Por um lado, conforme preconizam as legislações, defendem que os idosos sejam atendidos preferencialmente em seus lares; por outro lado, há o reconhecimento da necessidade de atendimento em outras instituições.

$\mathrm{Na}$ atuação profissional observou-se também que, por conta da insuficiência de vagas, o abrigamento público somente é efetivado pelas instituições municipais com o pedido do MP. Dessa forma, instaura-se um mecanismo dificultador e com ele outros critérios de elegibilidade geralmente são acrescidos. Uma vez que o abrigamento é previsto quando também há "carência material", as legislações colocam questões que novamente recaem sobre a família. O acesso dos idosos ao benefício previdenciário ou assistencial pode descaracterizar a ausência de con- dições financeiras de subsistência e dificultar o seu abrigamento em instituições públicas. Assim, embora o sistema de seguridade social tenha sido pensado para funcionar de forma integrada, na prática há separação das ações e dificuldade de articulação, que se traduzem em focalização e fragmentação das políticas com imposição de condicionantes que podem gerar desproteção, por considerar pontualmente as necessidades do indivíduo.

Em meio a isso, o idoso com acesso a benefício previdenciário ou assistencial, que tenha referência familiar e avalie a necessidade de viver em uma instituição de longa permanência, provavelmente não será atendido em instituição de abrigamento público, bem como terá dificultado o acesso a entidades privadas que em geral exigem valores superiores aos seus proventos. Ademais, cada ILPI institui um perfil de idoso a ser atendido, e corresponder a tais critérios nem sempre é possível.

Há condições diferenciadas de institucionalização. Os elementos acima apontados referem-se a instituições públicas e/ou conveniadas com o Estado, visto também que os idosos citados não possuem recursos para o pagamento de mensalidades em ILPI de natureza privada. Cabe apontar que, na minha prática profissional, foram visitados também idosos em ILPIs que se mostraram favoráveis ao abrigamento. Esses casos são esporádicos e referem-se àqueles que o solicitaram por conta própria ou consentiram com avaliações feitas por familiares. $\mathrm{O}$ acolhimento desses idosos geralmente é em instituições que lhes oferece quartos individuais e alguma privacidade. Além disso, eles mantêm vínculos com familiares e amigos.

Dessa forma, a questão de classe social interfere diretamente tanto no acesso aos serviços quanto na qualidade deles, pois os que detêm maior poder aquisitivo dispõem de opções em instituições de atendimento ou em suas próprias casas, com o acompanhamento necessário.

\section{Considerações finais}

Esta discussão pretendeu contribuir para a reflexão sobre as ações voltadas aos idosos e a necessidade de avanços na forma de a sociedade organizar suas instituições e os papéis que lhes atribui. Considera-se que a moralidade que atribui à família a proteção social como sua tarefa primordial é colocada nas legislações como dever. E este, por sua vez, é aceito por estar alicerçado em valores familistas que são socialmente compartilhados.

As leis são reflexos e ao mesmo tempo guias para as práticas. Isso contribui, por exemplo, para a afirmação de que existe abandono quando o idoso não conta com suporte familiar e/ou é abrigado, o que 
reporta a função de cuidar prioritariamente à família, e não a outras formas de fazê-lo. Esses pressupostos perpassam também concepções idealizadas da instituição familiar e seus papéis. De certo modo, é com o entendimento de que a família tem atribuições em prol do idoso que o Ministério Público fiscaliza as ações e que indivíduos a ele se dirigem para comunicar violações, justificar atos e avisar sobre alguns encaminhamentos feitos por familiares ou por terceiros.

Ao mesmo tempo em que se mantêm aspectos culturais e de cunho moral reportados para o aparato legal e para as práticas sociais, há dificuldades para o cumprimento da tarefa atribuída à família. Essas decorrem de mudanças na estrutura populacional, nos arranjos familiares, nos modos de inserção no trabalho e de organização doméstica e da forma de atuação do Estado, que se configura "mínimo" para o social, entre outras questões.

Além disso, no contexto atual, faz-se presente também uma concepção de que é possível envelhecer de modo saudável, responsabilizando os indivíduos por esse processo. A heterogeneidade da velhice é mascarada e as ações e políticas voltam-se prioritariamente para idosos com condições de participar no espaço público e que possam se integrar a grupos de convivência, ao trabalho e ao lazer. Sob a ideia de "melhor idade", é muitas vezes oculta a necessidade de ações para a velhice dependente.

Assim, indivíduos e suas famílias são vistos como principais responsáveis pela atenção às suas necessidades. A ação da sociedade e do Estado é prevista apenas quando comprovada a "incapacidade" individual e familiar, ou seja, esgotadas todas as possibilidades de ajustar indivíduo e família ao que é definido e consolidado como próprias atribuições. $\mathrm{O}$ embasamento familista e de expectativa de reciprocidade geracional corrobora também para a intervenção "mínima" do Estado no que se refere a recursos públicos para o atendimento das necessidades sociais.

Pode-se afirmar que há uma desigualdade na divisão entre família, sociedade e Estado da tão apregoada responsabilidade pela consolidação dos direitos do idoso. Assim, a instituição família deve primeiramente garantir a proteção, e as demais atuam para subsidiar e controlar as ações que desenvolvam ou não. Trata-se de uma configuração que também desenha hierarquicamente o que deve ser feito por cada uma das instituições.

Parte das demarcações de papéis pode ser observada, por exemplo, na delimitação da "situação de risco" como parâmetro para a atuação ou não do Ministério Público. Essa é definida não apenas como violação ou ausência de algum direito social, mas acima de tudo como incapacidade de o idoso e/ou de sua família reivindicarem esses direitos. As leituras e releituras dessas situações são feitas por funcioná- rios desse espaço estatal e não estão imunes a valores familistas e legalistas, que definirão não apenas se é demanda a ser contemplada ou recusada pela instituição, mas também quais ações são necessárias e o modo de operá-las.

Além disso, na afirmação e validação da "situação de risco" do idoso, nota-se que prevalecem características de "destituição" de sua condição humana. Os indícios que validam a existência do "risco", em geral, elencam condição de solidão - morar sozinho -, ausência de higiene, falta de alimentação, possíveis sinais de desorientação mental. Em consequência disso, e em parte dos casos, é anulada a possibilidade de escolha do idoso pela condução de sua vida e das formas de atendimento.

A conclusão de alguns dos procedimentos administrativos no MP dá-se na interdição civil do(a) idoso(a), o que conjuga as duas lógicas: legalista e moral/familista. Assim, se ele(a) não tem condições de buscar seus direitos, terá alguém legalmente constituído para fazê-lo e que geralmente é um familiar.

De modo geral, e não apenas nas políticas específicas para os idosos, o Estado continua pensando em "famílias funcionais" e não avança em políticas de apoio. A implementação e ampliação de formas diversas de atendimento, por exemplo, o Centro-Dia, previsto desde 1994 na Política Nacional do Idoso, conduziria ao não abrigamento de parcela significativa de idosos.

No que se refere à atuação do Serviço Social, embora não tenha sido o foco da discussão deste artigo, não há como ignorar que parte significativa dos procedimentos administrativos das Promotorias é constituída por documentos elaborados por assistentes sociais. Observa-se que algumas sugestões e apontamentos feitos por esses profissionais subsidiam a decisão dos promotores e são acatados por eles.

Cabe pontuar que a discussão aqui apresentada trouxe elementos de uma pesquisa que abarcou um período histórico e agregou elementos de observação e atuação profissional em Serviço Social na mesma instituição. Essas inserções trazem desafios diferentes para o estranhamento das questões. Além disso, a realidade institucional à qual pertencem os PAs analisados também se modifica no decorrer desse tempo, o que significa considerar que as análises aqui apresentadas são temporalizadas, e não definitivas, como também ocorre nos demais estudos de processos sociais que observam as relações sob o ponto de vista dos contextos históricos e em situações específicas.

Por fim, se nas intervenções voltadas aos idosos há contradições, lacunas e limites, existem conjuntamente possibilidades que devem ser plasmadas e fortalecidas, para que no processo histórico seja contemplada a heterogeneidade dos sujeitos que envelhecem e efetivados seus direitos. 


\section{Referências}

ALVES, Andréa Moraes. Os idosos, as redes de relações sociais e as relações familiares. In: NERI, Anita L. (Org.). Idosos no Brasil: vivências, desafios e expectativas na terceira idade. São Paulo: Perseu Abramo/Edições SESC, 2007.

ARRIAGADA, Irma. Estruturas familiares, trabalho e bem-estar na América Latina. In: ARAUJO, Clara; PICANÇO, Felícia; SCALON, Celi (Orgs.). Novas conciliações e antigas tensões? Gênero, família e trabalho em perspectiva comparada. Bauru, SP: EDUSC, 2007.

BLANCHET, Alain; GOTMAN, Anne. L'enquête et ses méthodes: l'entretien. Paris: Éditions Nathan, 1992.

BRASIL. Constituição da República Federativa do Brasil. Brasília, DF: Senado Federal/ Centro Gráfico, 1988. Disponível em: <http://www.planalto.gov.br/ccivil_03/ constituicao/constituicao.htm>. Acesso em: 29 set. 2013. Lei n. 8.842, de 4 de janeiro de 1994. Dispõe sobre a Política Nacional do Idoso, cria o Conselho Nacional do Idoso e dá outras providências. Disponível em: <http://www.planalto.gov.br/ccivil_03/leis/18842. htm>. Acesso em: 29 set. 2013.

Lei n. 10.741 de $1^{\circ}$ de outubro de 2003. Dispõe sobre o Estatuto do Idoso e dá outras providências. Disponível em: <http://www.planalto.gov.br/ccivil_03/ leis/2003/110.741.htm>. Acesso em: 29 set. 2013.

CAMARANO, Ana Amélia. Os novos idosos brasileiros muito além dos 60? Rio de Janeiro: IPEA, 2004.

Instituições de longa permanência e outras modalidades de arranjos domiciliares para idosos. In: NERI, Anita L. (Org.). Idosos no Brasil: vivências, desafios e expectativas na terceira idade. São Paulo: Perseu Abramo/ Edições SESC, 2007.

CAMARANO, Ana Amélia; PASINATO, Maria Tereza. $O$ envelhecimento populacional na agenda das políticas públicas. In: CAMARANO, Ana Amélia (Org.). Os novos idosos brasileiros muito além dos 60? Rio de Janeiro, IPEA, 2004.

CARVALHO, Maria do Carmo B. de. Famílias e políticas sociais. In: ACOSTA, Ana R.; VITALE, Maria Anália F. (Org.). Família, redes, laços e políticas públicas. 3. ed. São Paulo: Cortez, 2007.

COUTINHO, Maria Lúcia R. Transmissão geracional e família na contemporaneidade. In: LINS DE BARROS, Myriam M. (Org.). Família e geração. Rio de Janeiro: FGV, 2006.

DEBERT, Guita G.; OLIVEIRA, Amanda M. O idoso, as delegacias de polícia e os usos da violência doméstica. In: MORAES, Aparecida F.; SORJ, Bila (Orgs.). Gênero, violência e direitos na sociedade brasileira. Rio de Janeiro: 7 Letras, 2009.

DELGADO, Josimara; FLOR, Cristiane S. V. Políticas sociais para idosos: algumas reflexões a partir do enfoque de gênero. Mediações. Revista de Ciências Sociais, v. 12, n. 2, Universidade Estadual de Londrina, 2012.

DUARTE, Luis F. D.; GOMES, Edlaine de C. Três famílias: identidades e trajetórias transgeracionais nas classes populares. Rio de Janeiro: FGV, 2008.

ENGEL, Cíntia. Dependência e estratégias de cuidado no Brasil. Mediações. Revista de Ciências Sociais, v. 12, n. 2, p. 166-180, 2012.

FONSECA, Claúdia. De família, reprodução e parentesco: algumas considerações. Dossiê Famílias em Movimento. Cadernos Pagu, n. 29, jul./dez. 2007.

GOLDANI, Ana Maria. Reiventar politicas para familias reinventadas: entre la "realidade" brasileña y la utopia. In: ARRIAGADA, Irma (Ed.). Politicas hacia las familias, proteccion $y$ inclusión sociale. Santiago de Chile: Naciones Unidas/CEPAL, 2005. p. 319-345. (Série Seminarios y Conferencias, n. 4).

GOLDMAN, Sara N. As dimensões sociopolíticas do envelhecimento. In: PY, L; PACHECO, J. L.; SÁ, J. L. M; GOLDMAN, S. N. (Orgs.). Tempo de envelhecer: percursos e dimensões psicossociais. Rio de Janeiro: NAU Editora, 2004.

GUEDES, Simoni L.; LIMA, Michelle da S. Casa, família nuclear e redes sociais em bairros de trabalhadores. In: LINS DE BARROS, Myriam (Org.). Família e gerações. Rio de Janeiro: FGV, 2006.

IBGE. Instituto Brasileiro de Geografia e Estatística. Síntese de indicadores sociais uma análise das condições de vida da população brasileira 2010. Estudos e Pesquisas Informação Demográfica e Socioeconômica. n. 27, Rio de Janeiro, 2010. Disponível em: <http://www.ibge. gov.br/home/estatistica/populacao/condicaodevida/ indicadoresminimos/sinteseindicsociais2010/SIS_2010. pdf>. Acesso em: 28 out. 2011.

JELIN, Elisabeth. Genero y família en la política pública: una perspectiva comparativa Argentina-Suecia. Interseções: Revista de Estudos Interdisciplinares, ano 11, n. 2, Rio de Janeiro: Contra Capa Livraria/UERJ/NAPE, 2009.

LEMOS, Carlos E. S.; OLIVEIRA, Cecília S.; ALMEIDA, Luiz Cláudio C. de. Se a velhice for dependente - quem cuidará de você? In: CONGRESSO INTERNACIONAL INTERDISCIPLINAR EM SOCIAIS E HUMANIDADES. Anais... Niterói, RJ, 3 a 6 de setembro de 2012. Disponível em: <http://www. aninter.com.br/ANAIS>. Acesso em: 13 dez. 2012.

LINS DE BARROS, Myriam M. Autoridade e afeto: avós, filhos e netos na família brasileira. Rio de Janeiro: Jorge Zahar, 1987.

Envelhecimento, cultura e transformações sociais. In: PY, L.; PACHECO, J. L.; SÁ, J. L. M.; GOLDMAN, S. N. (Orgs.). Tempo de envelhecer: percursos e dimensões psicossociais. Rio de Janeiro: NAU Editora, 2004. MINAYO, Maria C. Violência contra idosos: o avesso do respeito à experiência e à sabedoria. Brasília: Secretaria Especial de Direitos Humanos, 2004.

MIOTO, Regina C. A família como referência nas políticas públicas: dilemas e tendências. In: TRAD, Leny 
A. B. (Org.). Família contemporânea e saúde: significados, práticas e políticas públicas. Rio de Janeiro: Fiocruz, 2010. p. 51-66.

PASINATO, Maria T.; KORNIS, George E. M. Texto para discussão, n. 1371. Rio de Janeiro: IPEA, 2009. (Série Seguridade Social)

PEIXOTO, Clarice E. Relações intergeracionais: da solidariedade aos maus-tratos. Interseções: Revista de Estudos Interdisciplinares, ano 11, n. 2, p. 407-418. Rio de Janeiro: Contra Capa Livraria/UERJ/NAPE, 2009.

Sobre a institucionalização da velhice e as condições de asilamento. In: GOLDEMBERG, Mirian. Corpo, envelhecimento e felicidade. Rio de Janeiro: Civilização Brasileira, 2011.
STEFFENON, Rosanete. Abrigamento de idosos: situações documentadas no Ministério Público do Estado do Rio de Janeiro. Dissertação (Mestrado em Serviço Social) Escola de Serviço Social, Universidade Federal do Rio de Janeiro, Rio de Janeiro, 2013.

VIANNA, Adriana de R. B. Limites da menoridade: tutela, família e autoridade em julgamento. Tese (Doutorado em Antropologia Social) - Programa de Pós-Graduação em Antropologia Social do Museu Nacional, Universidade Federal do Rio de Janeiro, Rio de Janeiro, 2002.

WONG, Laura L. R.; CARVALHO, J. A. O rápido processo de envelhecimento populacional do Brasil: sérios desafios para as políticas públicas. Revista Brasileira de Estudos Populacionais, v. 23, n. 1, p. 5-26, jun. 2006.

\title{
Elderly care: situations documented in the Public Prosecutor's Office of the State of Rio de Janeiro
}

\begin{abstract}
In recent decades we observe changes in the population structure, the legal framework, the family and other institutions, which, among other things, helps to put into question the care to the elderly population. Thus, this article presents situations where, due to not having elderly basic social rights effected in full, has fired the Public Prosecutor's Office of the State of Rio de Janeiro, through its Prosecutor of the Elderly. Thus, this paper reveals situations documented in administrative procedures and prosecutors of those notes as seniors, families, and others involved in needs and indications for seniors who live in long-stay institutions.
\end{abstract}

Key words: elderly, family, laws, situations, Prosecutor of the Elderly.

\section{Cuidado de ancianos: situaciones documentadas en el Ministerio Público del Estado de Río de Janeiro}

\section{Resumen}

En las últimas décadas se observan cambios en la estructura de la población, el marco legal, la familia y otras instituciones, que, entre otras cosas, ayudan a poner en discusión la atención dispensada a la población de edad avanzada. Por lo tanto, en este artículo se presentan situaciones en las que, debido a que los mayores no tienen derechos sociales básicos efectivados en su totalidad, se ha solicitado la intervención de la fiscalía del Estado de Río de Janeiro, a través del Ministerio de la Tercera Edad. Así, el artículo presenta situaciones documentadas en los procedimientos administrativos y fiscales de dichas fiscalías y nota cómo las personas mayores, las familias y otras personas partícipes hacen frente a necesidades no cubiertas e indicaciones para que las personas mayores vivan en instituciones de larga estancia.

Palabras clave: adultos mayores, familia, leyes.

Data de recebimento do artigo: 9/12/2013

Data de aprovação do artigo: 6/8/2014 